\title{
Site-specific delivery of ethanehydroxy diphosphonate from refillable polyurethane reservoirs to inhibit bioprosthetic tissue calcification
}

\author{
T.P. Johnston ${ }^{1}$, C.L. Webb ${ }^{2}$, F.J. Schoen ${ }^{3}$ and R.J. Levy ${ }^{4}$ \\ 'Department of Pharmaceutics, (M/C 880), College of Pharmacy, University of Illinois at Chicago (UIC), Chicago, IL, USA \\ ${ }^{2}$ Department of Cardiology, Children's Memorial Hospital, Chicagn, IL, USA \\ ${ }^{3}$ Department of Pathology, Brigham and Women's Hospital and Harvard Medical School, Boston, MA, USA \\ ${ }^{4}$ Division of Pediatric Cardiology, University of Michigan, Kresge II Research Laboratories, Ann Arbor, MI, USA
}

(Received 5 October 1992; accepted in revised form 11 February 1993)

Calcification (CALC) is the most frequent cause for the failure of bioprosthetic heart valves fabricated from glutaraldehyde-pretreated porcine aortic valve, and contributes to the failure of glutaraldehyde pretreated bovine pericardial ( $\mathrm{BHV}$ ) bioprosthetic heart valves as well. Although systemic therapy in rats using ethanehydroxy diphosphonate (EHDP) has proven successful in inhibiting CALC, adverse effects on serum calcium, bone development, and overall somatic growth have been noted. The present study was designed to evaluate the potential of site-specific delivery of EHDP to arrest CALC of glutaraldehyde-pretreated bovine pericardium when implanted subdermally in rats using a refillable rescrvoir drug delivery device. The refillable reservoir devices evaluated in these studies exhibited constant (zero-order) release of EHDP in vitro and replenishment of the drug supply when implanted subdermally in rats was achieved in a noninvasive fashion using an exteriorized entrance and exit cannula. The refillable reservoirs evaluated were fabricated from a commercially available polyurethane $\left(\right.$ Biomer $^{\mathrm{TM}}$ ). Glutaraldehyde-pretreated bovine pericardium was implanted subdermally in 21-day-old rats either alone (control) or with refillable Biomer ${ }^{\mathrm{TM}}$ reservoirs with (treatment) or without (sham) a $2 \mathrm{M}$ solution of $\mathrm{Na}_{2} \mathrm{EHDP}$. Implanted reservoirs which initially contained a $2 \mathrm{M}$ solution of $\mathrm{Na}_{2} \mathrm{EHDP}$ were refilled with a fresh $2 \mathrm{M}$ solution of $\mathrm{Na}_{2} \mathrm{EHDP}$ on days 7 and 14 post-initial surgery using a syringe and the exteriorized entrance and exit cannulas. Pericardium retrieved following 21 days and assayed for calcium showed significant $(P<0.001)$ inhibition in CALC for tissue implanted adjacent to refillable Biomer ${ }^{\mathrm{TM}}$ reservoirs containing EHDP $(6.9 \pm 2.1 \mu \mathrm{g} / \mathrm{mg})$ compared to control $(179.0 \pm 13.5 \mu \mathrm{g} / \mathrm{mg})$ and sham-implanted $(152.0 \pm 10.2 \mu \mathrm{g} / \mathrm{mg})$ rats. Unimplanted pericardium had a mean tissue calcium concentration of $3.0 \pm 0.5 \mu \mathrm{g} / \mathrm{mg}$. Based on the in vitro release studies of EHDP from refillable Biomer ${ }^{\mathrm{TM}}$ reservoirs, the estimated dose delivered when implanted subdermally in rats in the present study was $5.5 \pm 0.7 \mathrm{mg} / \mathrm{kg}$ per day. For rats implanted with EHDPcontaining refillable reservoirs, histological examination of retrieved pericardium and femurs from rats in each group confirmed both complete inhibition of CALC of the glutaraldehyde crosslinked

Correspondence to: Thomas P. Johnston, Ph.D., Department of Pharmaceutics (M/C 880 ), College of Pharmacy, University of llinois at Chicago, 833 South Wood Street, Chicago, IL 60612, USA. Tel. (312) 996-2365; Fax (312) 996-0098. 
pericardium and no untoward effects on bone development, respectively. In addition, blood samples obtained at sacrifice showed no change in serum $\mathrm{Ca}^{2+}$ concentrations in EHDP-treated animals compared to controls. Thus, the site-specific delivery of EHDP using refillable Biomer ${ }^{\mathrm{TM}}$ reservoirs was successful for inhibiting BHV CALC in a rat subdermal model with no untoward effects on bone development, serum $\mathrm{Ca}^{2+}$ concentrations, or overall growth. The advantages of the refillable reservoir system are its constant (zero-order) rate of EHDP release and its potential for replenishment of EHDP by noninvasive means when the EHDP solution inside the reservoir has been depleted.

Key words: Bioprosthetic heart valve; Calcification; Controlled release; Ethanehydroxy diphosphonate; Glutaraldehyde; Polyurethane

\section{Introduction}

Calcification (CALC) of biomaterial implants such as glutaraldehyde pretreated bovine pericardium (BHV) or porcine aortic valve tissue used in the fabrication of bioprosthetic heart valves still remains an important clinical problem. Mineralization ultimately leads to destruction of the biomaterial which results in subsequent patient morbidity and/or mortality. Presently, there is no effective therapy to arrest the calcification process following implantation of BHV [1]. Experimental animal models have been extensively employed to elucidate both the mechanism of the calcification process and define possible treatment strategies. Fortunately, these animal models yield comparable pathology to clinically retrieved valves. Thus, animal models have proven invaluable for understanding factors contributing to the calcification process and for reproducing at an accelerated rate the calcific lesions observed in clinically retrieved BHV.

Animal models that have been used to study calcification of bioprosthetic heart valve tissue include large animal circulatory implants [2-6] and subcutaneous implants in rodents [7-8] and rabbits [9]. Ethanehydroxy diphosphonate (EHDP) has been shown to effectively inhibit experimental calcification [10-11]. However, when EHDP was administered subcutaneously to immature rats at doses exceeding $15 \mathrm{mg} / \mathrm{kg}$ per day, adverse systemic effects were observed [12]. Specifically, adverse effects in rats when administered EHDP at a dose greater than $15 \mathrm{mg} / \mathrm{kg}$ per day included retarded overall growth of animals, impaired bone development, and elevated serum $\mathrm{Ca}^{2+}$ levels [12]. Thus, while EHDP was a potent inhibitor of $\mathrm{BHV}$ calcification, direct parenteral administration of an EHDP solution to rats was shown to result in adverse systemic effects at doses necessary to inhibit calcification of implanted tissue. Recently, it has been shown that the site-specific administration of EHDP to rats implanted with BHV tissue and coimplanted with any one of a variety of drug delivery devices has resulted in the prevention of BHV CALC. Drug delivery devices/systems which have been evaluated for inhibition of BHVCALC when coimplanted with BHV tissue in rats include monolithic matrices containing EHDP composed of either polydimethylsiloxane or ethylene-vinyl-acetate $(6,10-11,13-16)$, mini-osmotic pumps [10], polyurethane matrices [17], and nonrefillable, polyurethane reservoirs [18]. The latter drug delivery system has the advantage of zero-order release of EHDP provided a supersaturated solution of EHDP is maintained in the lumen of the reservoir device. However, a reservoir device containing a saturated solution of EHDP will eventually exhibit an exponential (first-order) release rate when the EHDP solution is of nonconstant thermodynamic activity. Thus, this necessitates that a reservoir device be refillable following depletion of EHDP to a concentration defined by the solubility product equilibrium constant, $K_{\mathrm{sp}}$, for EHDP in an aqueous solution. At a time corresponding to the point where the EHDP solution will be no longer saturated with respect to EHDP, the reservoir device should be refilled with a fresh saturated 
solution of EHDP to reinitiate delivery of EHDP at a constant (zero-order) rate.

The purpose of the present investigation was to characterize and evaluate refillable polyurethane reservoirs with regard to release of EHDP in vitro into a receptor phase with or without a physiological concentration of $\mathrm{Ca}^{2+}$, and a qualitative assessment of the surface morphology of the explanted reservoirs. In addition, the refillable polyurethane reservoirs were assessed for efficacy at inhibiting CALC of glutaraldehyde-pretreated bovine pericardium implanted subdermally in rats for 21 days.

\section{Experimental}

\section{Materials}

Disodium ethanehydroxydiphosphonate ( $\mathrm{Na}_{2} \mathrm{EHDP}$ ) was provided by Norwich Eaton (Norwich, NY). $\mathrm{Na}_{2}\left[{ }^{14} \mathrm{C}\right]$ EHDP (specific activity; $48.9 \mu \mathrm{Ci} / \mathrm{mmol}$ ) was generously supplied by Procter and Gamble (Cincinnati, OH). Hydroxyethylpiperazinc-N'-2-cthancsulfonic acid (HEPES) buffer was obtained from Sigma (St. Louis, MO). Ketamine hydrocholoride $(100 \mathrm{mg} /$ $\mathrm{ml})$ and pentobarbital sodium $(2.5 \mathrm{~g} / 50 \mathrm{ml})$ were obtained from the University of Illinois hospital pharmacy (Chicago, IL). Syringes used in the in vitro and in vivo studies were $1 \mathrm{ml}$ tuberculin syringes fitted with a 19.5 gauge, 1.5 -in needle; both types were obtained from Becton Dickinson Company (Rutherford, NJ). Sterile, nonabsorbable surgical suture (silk 3-0, MS/8) was purchased from Ethicon, Inc. (Sommerville, $\mathrm{NJ}$ ). Aqua-Sol ${ }^{\mathrm{R}}$ scintillation solution was purchased from Research Products, Inc. (Rockford, IL).

Glutaraldehyde pretreated bovine pericardium (BHV) was prepared as follows: parietal bovine pericardium was obtained fresh at slaughter from steers and immediately incubated in iced sterile saline for not longer than 1 h. Following dissection of superficial fat from the external surfaces, the pericardium was transferred to $0.8 \%$ glutaraldehyde (E.M. Grade, Polysciences, Warrington, PA) in a physiological buffer (0.05 M HEPES in $0.1 \mathrm{M} \mathrm{NaCl}, \mathrm{pH}=7.4)$ for a 2-week period to initiatc cross-linking.

\section{Methods}

\section{Refillable reservoirs}

The refillable circular $(\mathrm{dia}=1.27 \mathrm{~cm}$; surface area available for diffusion $=A=2.53 \mathrm{~cm}^{2}$ ) reservoirs consisted of polyurethane $\left(\right.$ Biomer $^{\mathrm{TM}}$ ) sheeting and were fabricated by Thermedics, Inc. (Woburn, MA). A polypropylene tube $($ dia $=0.159 \mathrm{~cm})$ entered and exited the lumen of each refillable reservoir device. The polypropylene refilling tube was discontinuous between the point of entry and exit from the reservoir lumen. The polyurethane sheeting used to construct the circular reservoirs was approximately $0.0105 \pm 3.6 \times 10^{-4} \mathrm{~cm}$ thick. The volume of solution that could be instilled into an individual reservoir lumen was approximately $150 \mu \mathrm{l}$. A typical refillable polyurethane reservoir device with entrance and exit tubes is illustrated in Fig. 1.

\section{In vitro release of $\left[{ }^{14} C\right] E H D P$}

Reservoirs $(n=3)$ containing a supersaturated (2 M) solution of $\left[{ }^{14} \mathrm{C}\right]$ EHDP were suspended, but completely immersed, in $5 \mathrm{ml}$ of a physiological buffer (0.05 M HEPES adjusted to $0.15 \mathrm{M}$ with $\mathrm{NaCl}, \mathrm{pH}=7.4$ ) contained in $20 \mathrm{ml}$ glass vials. The reservoir entrance and exit tubes were oriented in a vertical position such that the longer entrance tube (6-7 in) exited the glass vial. A syringe containing a $2 \mathrm{M}$ solution of $\left[{ }^{14} \mathrm{C}\right]$ EHDP was attached to the end of the entrance tube and positioned vertically above the diffusion system. The reservoirs were then filled by injection of $0.15 \mathrm{ml}$ of the $\left[{ }^{14} \mathrm{C}\right]$ EHDP solution and the end of the exit tube closed by flame sealing. Each $5 \mathrm{ml}$ aliquot of receptor phase at $22^{\circ} \mathrm{C}$ was continuously stirred with a magnetic stirring bar powered by a magnetic stirring plate that was situated below the diffusion apparatus. At specified time points during the 9 day in vitro release/diffusion study, $1 \mathrm{ml}$ aliquots of the receptor phase were withdrawn from each vial, combined with $15 \mathrm{ml}$ of scintillation solution, and counted on a Beckman liquid scintillation 


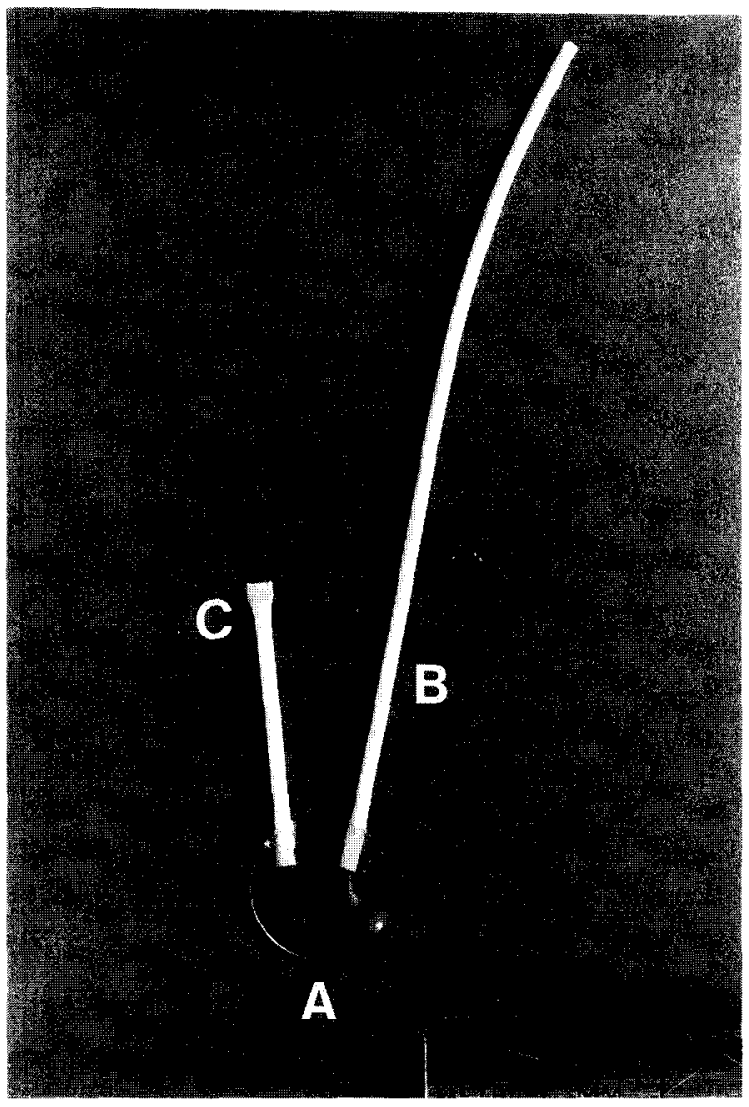

Fig. 1. An empty polyurethane refillable reservoir used to deliver EHDP locally to BHV coimplanted in rats. (a) The polyurethane rescrvoir. (b) The longer cntrance refilling tubc.

(c) The shorter exit tube.

counter (model \#5801, Berkeley, CA). One ml of fresh receptor phase was added to each vial containing a reservoir following removal of the 1 $\mathrm{ml}$ sample for $\left[{ }^{14} \mathrm{C}\right] \mathrm{EHDP}$ analysis to maintain sink conditions and a constant receptor phase volume of $5 \mathrm{ml}$. Syringes containing the $2 \mathrm{M}$ solution of $\left[{ }^{14} \mathrm{C}\right] \mathrm{EHDP}$ were positioned above the diffusion system so that refilling of the reservoirs, if desired, could be conveniently performed following the termination of the steadystate portion of the diffusion profile.

A second in vitro diffusion study was conducted to investigate any potential alteration in release rate that might arise when the receptor phase contained a physiological concentration of $\mathrm{Ca}^{2+}$ ion as would be encountered in a subcuta- neous environment. As described above, filled reservoirs $(n=3)$ werc allowed to release EHDP into a receptor phase $\left(22^{\circ} \mathrm{C}\right)$ similar in composition to that used above, but additionally containing $1.5 \mathrm{mM} \mathrm{Ca}^{2+}$ ion. This study was conducted in an attempt to more accurately characterize the release profile of EHDP anticipated in vivo.

\section{Rat subdermal studies}

Reservoirs identical to those used in the in vitro release studies were evaluated in vivo using the well established rat subdermal model of accelerated calcification [10-11]. Three groups of rats were used in assessing the efficacy of refillable reservoirs to inhibit the calcification of subdermally implanted bovine pericardium. All animals were anesthetized by intramuscular injection of ketamine hydrochloride using a dose of $10 \mathrm{mg} / 100 \mathrm{~g}$ of body weight. The first group of rats (3-week-old, male, Sprague Dawley, CD strain, Harlan Laboratories, Indianapolis, IN) were implanted on their dorsal side with glutaraldehyde-pretreated bovine pericardium (1.3 $\times 1.3 \mathrm{~cm}$ ) attached to an EHDP-containing reservoir device which had previously been incubated in HEPES buffer for 6 days $(\approx$ the value of the experimentally determined lag time, $t_{\text {lag }}$ ). Each piece of BHV tissue was situated adjacent to a refillable reservoir drug delivery device by suturing the biomaterial around the entrance and exit ports closest to the lumen of the device. This procedure served to minimize animal-induced movement of pericardium away from the refillable reservoir drug delivery device following subdermal implantation. The entrance and exit ports of the refillable reservoirs were then exteriorized approximately $2.5 \mathrm{~cm}$ below the back of the head midway between the ears and the wound subsequently closed using surgical staples and suture thread. The end of the shorter exit tube (1.8-2.0 in ) was flame sealed and allowed a free range of motion ex vivo in contrast to the entrance tube $(\approx 4-5$ in $)$ of the refillable reservoir device which was flame sealed and then stapled to the rodent's back using surgical staples. Empty reservoir devices adjacent to a piece of BHV tissue were each similarily implanted in a second 
group of rats to assess any anticalcification effects that might potentially be induced by the polyurethane membrane. The last group of rats were implanted with BHV tissue only and served as controls.

Based on our studies which evaluated the release of $\left[{ }^{14} \mathrm{C}\right] \mathrm{EHDP}$ in vitro from refillable reservoirs at $22^{\circ} \mathrm{C}$, the reservoirs should have been refilled with a fresh $2 \mathrm{M}$ solution of $\mathrm{Na}_{2} \mathrm{EHDP}$ at a time corresponding to the mean value of the $t_{\text {unsat }}$ listed in Table $1(\approx$ every $19.1 \pm 2.4$ days $)$ where $t_{\text {unsat }}$ is defined as the time required for the concentration of the $2 \mathrm{M} \mathrm{Na}_{2} \mathrm{EHDP}$ solution initially contained in the reservoir lumen to decrease to 1.5 M. However, our previous experimental findings with nonrefillable polyurethane reservoirs in vivo [18] suggested that enhanced release of EHDP could potentially occur due to animal movement. Thus, we selected a once weekly refilling schedule. Reservoirs which ini-

\section{TABLE 1}

Membrane transport parameters for EHDP diffusion through refillable biomer ${ }^{\mathrm{TM}}$ reservoirs

\begin{tabular}{|c|c|c|}
\hline \multirow[t]{2}{*}{ Parameter } & $\begin{array}{l}\text { Group } 1 \\
\text { (without } \mathrm{Ca}^{2+} \text { ) }\end{array}$ & $\begin{array}{l}\text { Group } 2 \\
\left(\text { with } \mathrm{Ca}^{2+} \text { ) }\right.\end{array}$ \\
\hline & Mean \pm S.D. & Mean \pm S.D. \\
\hline $\begin{array}{l}P^{\mathrm{a}} \times 10^{8} \\
(\mathrm{~cm} / \mathrm{s})\end{array}$ & $3.15 \pm 0.23$ & ${ }^{*} 0.91 \pm 0.11$ \\
\hline $\begin{array}{l}D^{\mathrm{b}} \times 10^{11} \\
\left(\mathrm{~cm}^{2} / \mathrm{s}\right)\end{array}$ & $3.44 \pm 0.0058$ & $3.40 \pm 0.021$ \\
\hline$K^{\mathrm{c}}$ & $9.62 \pm 0.72$ & $* 2.81 \pm 0.34$ \\
\hline $\begin{array}{l}\mathrm{d} M_{t} / \mathrm{d} t^{\mathrm{d}} \\
(\mathrm{mg} / \mathrm{day})\end{array}$ & $3.44 \pm 0.25$ & $* 0.99 \pm 0.12$ \\
\hline $\begin{array}{l}t_{\text {unsat. }} \\
\text { (days) }\end{array}$ & $5.5 \pm 0.41$ & $* 19.1 \pm 2.4$ \\
\hline $\begin{array}{l}\text { Estimated dose } \\
\text { in vivo }(\mathrm{mg} / \mathrm{kg} / \text { day })\end{array}$ & $19.1 \pm 1.4$ & $* 5.5 \pm 0.68$ \\
\hline
\end{tabular}

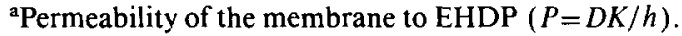

'Apparent diffusion coefficient.

cApparent partition coefficient.

'In vitro release rate.

'Time required for the concentration of the EHDP solution in the reseroir lumen to decrease to $1.5 \mathrm{M}$.

fBased upon a final total body weight of approximately 0.18 $\mathrm{kg}$ following the 21-day implant.

*Significant difference $(P<0.05)$ compared to the mean value of the transport parameter for Group 1 reseroirs.
}

tially contained a $2 \mathrm{M}$ solution of $\mathrm{Na}_{2}$ EHDP implanted in rats adjacent to bovine pericardium were refilled with a fresh $2 \mathrm{M}$ solution of $\mathrm{Na}_{2}$ EHDP on days 7 and 14. EHDP used in all in vivo studies was not radiolabelled.

All rats in each group were weighed both prior to implantation of the refillable reservoirs and/ or glutaraldehyde-pretreated pericardium and at the time of sacrifice to assess any potential disturbances in overall growth. Immediately following an overdose of pentobarbital sodium, a blood sample was obtained from each rat by cardiac puncture for determination of the serum $\mathrm{Ca}^{2+}$ concentrations. Reservoir drug delivery devices and glutaraldehyde-pretreated bovine pericardium were explanted following 21 days. Retrieved BHV tissue was minced, acid hydrolysed, and then assayed for calcium content by atomic absorption spectroscopy as described elsewhere [8]. In addition, serum $\mathrm{Ca}^{2+}$ concentrations for each rat were determined using atomic absorption spectroscopy [8].

\section{Reservoir refilling protocol}

Treatment animals were administered ketamine hydrochloride $(10 \mathrm{mg} / 100 \mathrm{gm}$ of body weight) by intraperitoneal injection on days 7 and 14. The animals were then individually placed in a restraint device (Fisher Scientific, Chicago, IL) and the previously flame-sealed end of the exit and entrance cannula removed using a scissors. A 1-ml tuberculin syringe containing a $2 \mathrm{M}$ solution of $\mathrm{Na}_{2} \mathrm{EHDP}$ was attached to the entrance cannula and the entire refillable reservoir system flushed with $0.5 \mathrm{ml}$ of fresh drug solution. The ends of the exit and entrance tubes were then flame sealed and the longer entrance tube restapled to the rat's back. Integrity of the refillable reservoir device was indirectly (qualitatively) confirmed by noting efflux of the $2 \mathrm{M}$ $\mathrm{Na}_{2} \mathrm{EHDP}$ solution from the exit cannula during the refilling procedure. Efflux of drug solution upon injection during the refilling procedure would suggest that the device was free from tears and/or perforations while implanted subdermally. This qualitative assessment of membrane/device integrity in vivo was correlated with microscopic evaluation of the explanted 
reservoir devices for surface defects as described below.

\section{Morphological analyses}

A representative section from all retrieved bovine pericardium was examined for CALC using light microscopy. Each piece of pericardium obtained at the time of sacrifice was immediately fixed in a cacodylate-buffered $2.5 \%$ glutaraldehyde- $2 \%$ paraformaldehyde solution buffered at $\mathrm{pH}=7.2$ [19] for $24 \mathrm{~h}$ and then dehydrated in graded ethanol solutions prior to embedding in glycolmethylmethacrylate (JB-4, Polysciences, Warrington, PA). Sections $(2-3 \mu \mathrm{m})$ were stained with hematoxylin and eosin for overall morphological analyses and Von Kossa's reagent for calcium phosphate localization [10]. In addition, femurs from three representative rats in each of the three groups were dissected away from attached muscle at the time of sacrifice and immediately fixed in $10 \%$ neutral buffered formalin (Sigma, St. Louis). No decalcification was performed on retrieved bone specimens. Bone specimens were then dehydrated, sectioned, and stained as described above for retrieved tissue specimens. Each growth plate was then evaluated histologically for any EHDP-induced changes.

\section{Reservoir membrane surface analysis}

Explanted reservoirs were allowed to air dry and then prepared for analysis of the polyurethane surface using scanning electron microscopy (SEM). Samples for scanning electron microscopy were sputtered under vacuum with carbon as previously described [20]. Scanning electron micrographs were obtained with a $\mathrm{Hi}$ tachi Model S-570 Scanning Electron Microscope (Hitachi Instruments, Santa Clara, CA).

\section{Data analysis}

All data from the in vitro release/diffusion studies was analysed individually for each reservoir. The diffusion profiles for $\left[{ }^{14} \mathrm{C}\right] \mathrm{EHDP}$ through the polyurethane membranes comprising the refillable reservoirs were expressed as the cumulative umol EHDP detected in the receptor phase versus time. Comparison of mean values of each parameter between groups in the in vivo studies was performed using 1-way analysis of variance (ANOVA) coupled with the method of Scheffe.

\section{Results}

\section{Release of EHDP in vitro from refillable polyurethane (Biomer ${ }^{\mathrm{TM}}$ ) reservoirs}

The in vitro diffusion of $\left[{ }^{14} \mathrm{C}\right]$ EHDP through the refillable polyurethane reservoirs into a receptor phase with and without a physiological concentration of $\mathrm{Ca}^{2+}$ is shown in Fig. 2. The mean values of pertinent transport parameters for $\left[{ }^{14} \mathrm{C}\right] \mathrm{EHDP}$ diffusion through the polyurethane reservoirs were calculated as described previously [21] and are listed in Table 1. Refillable reservoirs that were fabricated of Biomer ${ }^{\mathrm{TM}}$ and evaluated for the in vitro release of EHDP in the present study, in contrast to nonrefillable polyether-urea-urethane reservoirs in previous work [18], did not appear to imbibe receptor phase and swell despite a supersaturated solution of $\left[{ }^{14} \mathrm{C}\right]$ EHDP contained in the reservoir lumen. However, the apparent lack of buffer influx noted in the present study may have potentially been due to the relatively small volume of saturated EHDP solution contained in each reservoir device. Moreover, the mean value of the

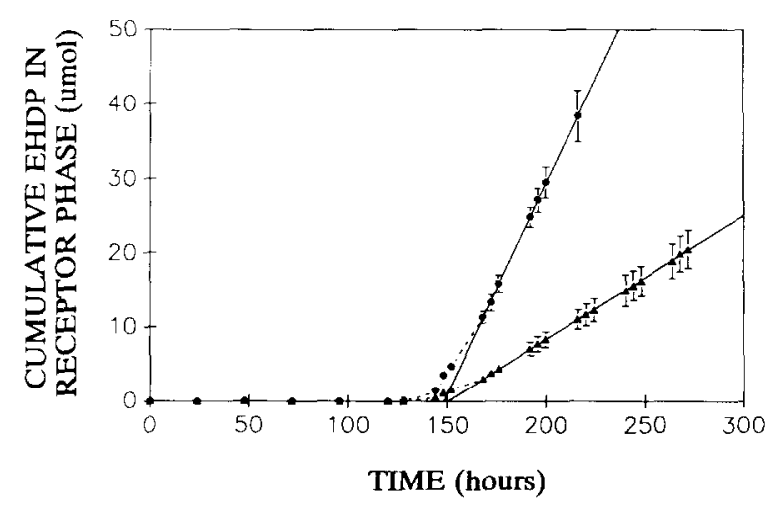

Fig. 2. Diffusion of $\left[{ }^{14} \mathrm{C}\right]$ EHDP through refillable polyurethane (Biomer ${ }^{\mathrm{TM}}$ ) reservoirs. Fach symbol represents the mean value of the cumulative mass (umol) of EHDP released into a physiological buffer with (4) or without (•) $\mathrm{Ca}^{2+}$. 
percentage of $\left[{ }^{14} \mathrm{C}\right]$ EHDP released from the refillable reservoir devices by diffusion was $5.4 \% \pm 0.68$ at $t=248 \mathrm{~h}$ and $9.8 \% \pm 0.72$ at $t=200$ $h$ for reservoirs evaluated for release of EHDP into a receptor phase with or without a physiological concentration of $\mathrm{Ca}^{2+}$, respectively. It was decided to terminate the in vitro studies of EHDP diffusion into a receptor phase with $\mathrm{Ca}^{2+}$ ion present or absent at 272 and $216 \mathrm{~h}$, respectively because the entire receptor phase could not be completely removed and replaced with fresh buffer at each sampling time point. Instead, as described above, the receptor phase was continuously sampled and analysed for the appearance of $\left[{ }^{14} \mathrm{C}\right] \mathrm{EHDP}$. It is generally well accepted that the drug concentration in the receptor phase must not exceed approximately $10 \%$ of the concentration in the donor compartment (reservoir lumen ) to maintain sink conditions in the receptor phase [22].

The in vitro release rates of EHDP from refillable reservoirs calculated from the steady-state portions of the diffusion profiles shown in Fig. 2 demonstrate an approximate 3.5 -fold reduction in the release rate of EHDP when the receptor phase contained a physiological concentration of $\mathrm{Ca}^{21}$ (Table 1). Therefore, an approximate 3.5fold increase in the mean value of $t_{\text {unsat }}$ would be expected for reservoirs allowed to release EHDP into a receptor phase containing $1.5 \mathrm{mM} \mathrm{Ca}^{2+}$. In addition, the mean values of the experimentally-determined lag times were not significantly different $(P>0.05)$ for EHDP transport through the reservoir membranes into both receptor phases evaluated. Hence, as expected, the mean values of the diffusion coefficient were not significantly different (Table 1 ). However, there was an approximate 3.5 -fold reduction in the mean value of the partition coefficient for reservoirs allowed to release EHDP into a physiological buffer containing $1.5 \mathrm{mM} \mathrm{Ca}^{2+}$. Since mean values of the diffusion coefficient were not significantly different when EHDP was allowed to diffuse in vitro into buffer either with or without a physiological concentration of $\mathrm{Ca}^{2}$, it follows that a 3.5-fold reduction in the mean value of the partition coefficient would result in an approxi- mate 3.5-fold reduction in the mean value of the membrane permeability $(P=D K / h)$ for reservoirs evaluated for EHDP release into buffer containing $1.5 \mathrm{mM} \mathrm{Ca}^{2+}$.

\section{Efficacy of reservoir-delivered EIIDP to inhibit CALC of glutaraldehyde-pretreated pericardium}

As listed in Table 2, CALC of BHV was completely inhibited when implanted adjacent to EHDP-loaded refillable reservoirs in rats. The mean value of tissue calcium concentration determined for tissue which had been implanted in rats adjacent to EHDP-filled reservoirs for 21 days $(6.9 \pm 2.1 \mu \mathrm{g} / \mathrm{mg})$ was significantly $(P<0.001)$ less than $\mathrm{Ca}^{2+}$ concentrations determined for control tissue $(179.0 \pm 13.5 \mu \mathrm{g} / \mathrm{mg})$. Empty reservoirs coimplanted with pericardium afforded no inherent protection from tissue calcium deposition $(152.0 \pm 10.2 \mu \mathrm{g} / \mathrm{mg})$ when compared to controls (Table 2 ). No significant difference was found for serum $\mathrm{Ca}^{2+}$ concentrations for the 3 groups listed in Table 2, although serum $\mathrm{Ca}^{2+}$ concentrations were slightly elevated in both sham and EHDP-treated rats compared to controls. Lastly, no retardation in overall somatic growth was observed for EHDPtreated and sham-implanted animals when compared to control animals (Table 2 ).

TABLE 2

Inhibition of calcification of glutaraldehyde-pretreated bovine pericardium using site-specific delivery of EHDP from refillable polyurethane reservoirs (21-day implants)

\begin{tabular}{lrccc}
\hline $\begin{array}{l}\text { Experimental } \\
\text { group }\end{array}$ & $n$ & $\begin{array}{l}\text { Tissue } \mathrm{Ca}^{2+} \\
(\mu \mathrm{g} / \mathrm{mg})\end{array}$ & $\begin{array}{l}\text { Serum } \mathrm{Ca}^{2+} \\
(\mathrm{mg} / \mathrm{dl})\end{array}$ & $\begin{array}{l}\text { Growth } \\
\text { (weight as \% } \\
\text { of controls) }\end{array}$ \\
\hline $\begin{array}{l}\text { Unimplanted } \\
\text { Control }\end{array}$ & 7 & $3.0 \pm 0.5^{\mathrm{a}, \mathrm{b}}$ & - & - \\
Reseroir (sham) & 10 & $152.0 \pm 10.2$ & $13.4 \pm 1.73$ & $98.3 \pm 1.2$ \\
$\begin{array}{l}\text { EHDP-filled } \\
\text { reservoirs }\end{array}$ & 8 & $6.9 \pm 2.1^{\mathrm{b}}$ & $15.5 \pm 4.8$ & $99.1 \pm 2.0$ \\
\hline
\end{tabular}

aMean value \pm standard error of the mean value (SEM).

bignificant difference $(P<0.001)$ compared to the mean value for controls.

'From Johnston et al., J. Pharm. Sci., 77 (1988) 740. 

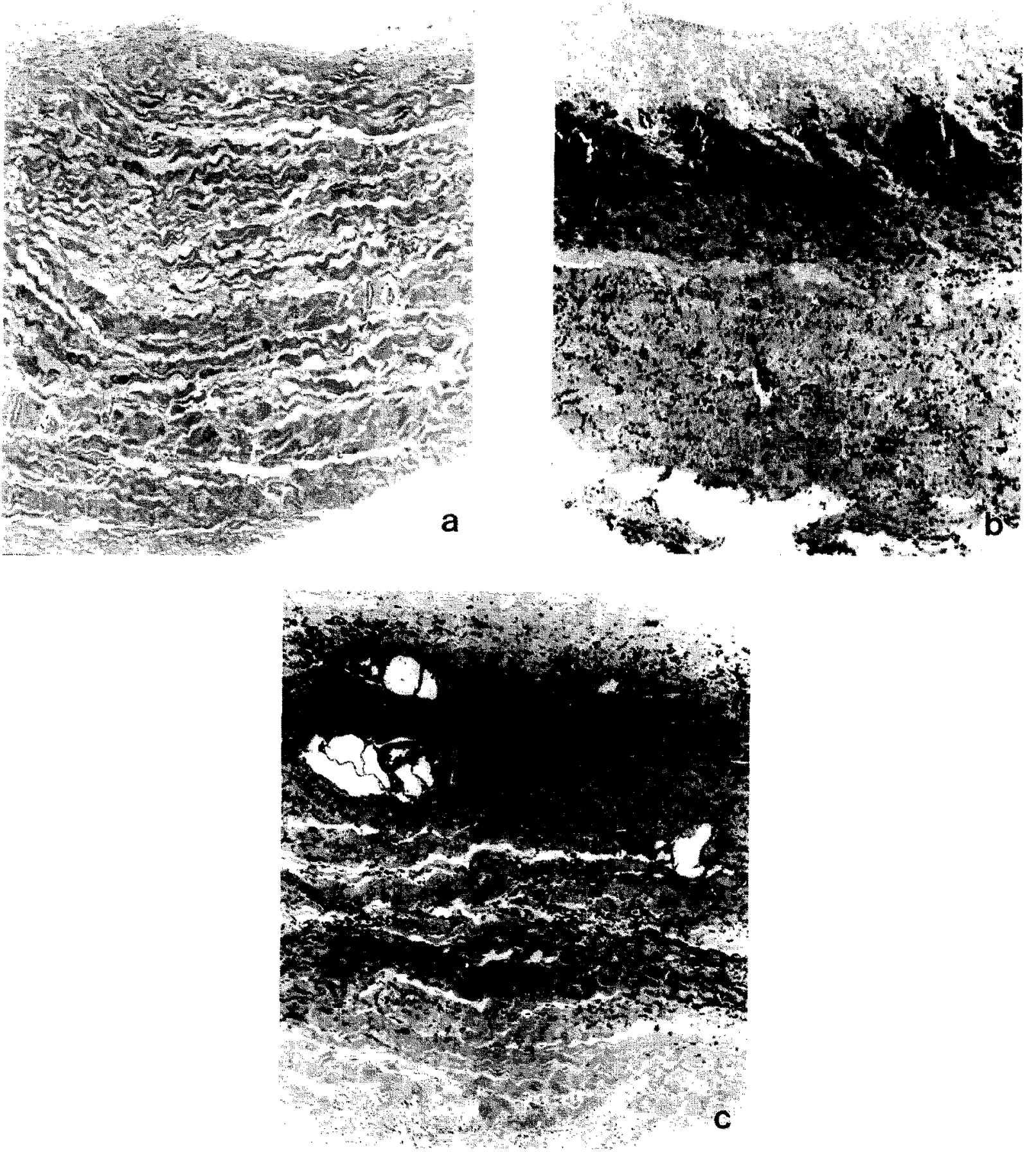

Fig. 3. Photomicrographs of pericardial tissue implanted subdermally, adjacent to drug-containing reservoirs and controls, for 21 days. (a) Tissuc implanted adjacent to drug-containing rescrvoir, (b) tissuc implanted adjacent to reservoir not containing drug and (c) pericardium implanted without reservoir or drug. (a) is free of calcification while (b) and (c) demonstrate diffuse calcification. Von Kossa stain (calcium phosphates black), magnification $160 \times$. 

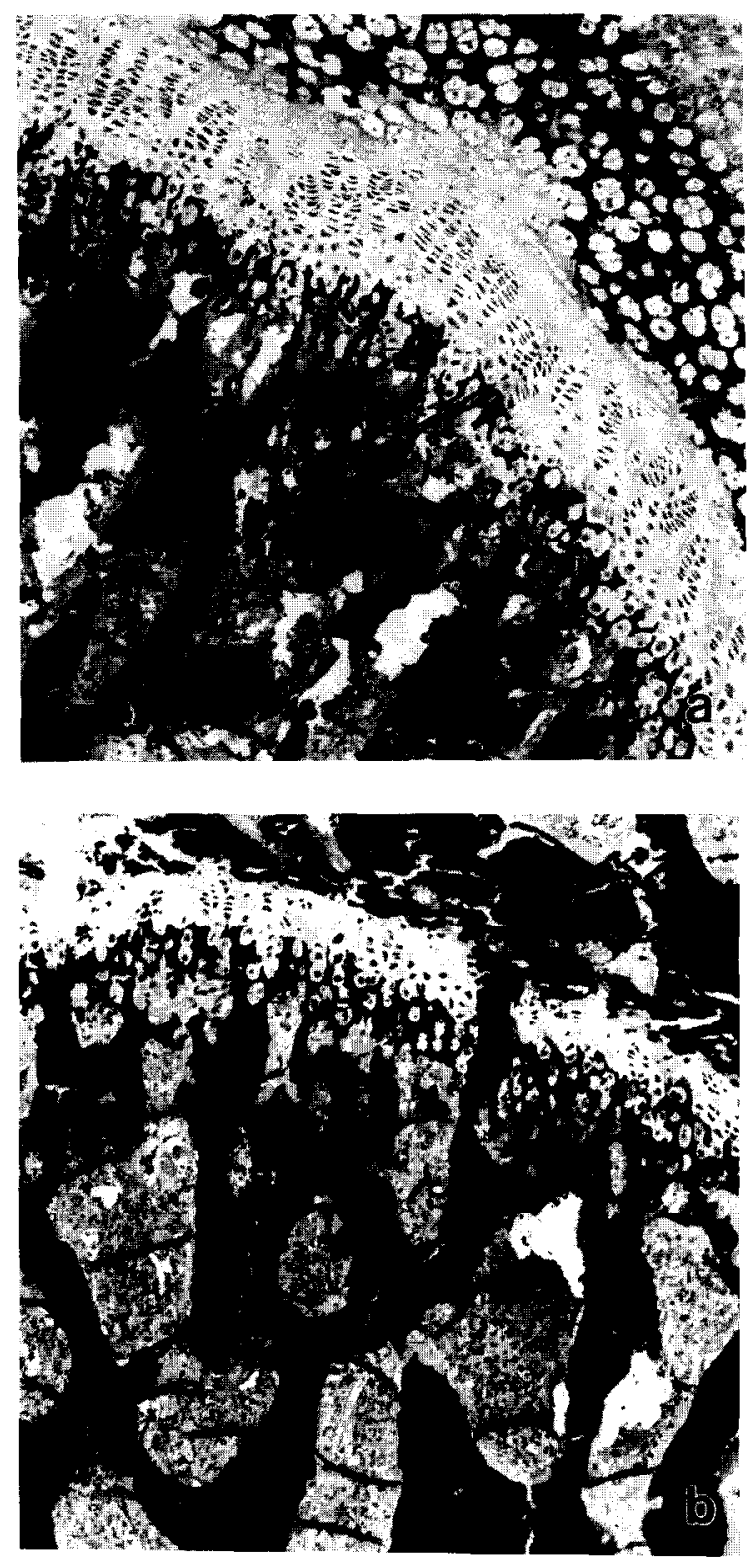

Fig. 4. Femoral epiphyseal growth plates from rats receiving EHDP-containing reservoirs and those without drug. (a) Femur from reservoir-delivered drug recipient. (b) Femur from animal receiving no drugs. Mineralization is morphologically normal in each case. Von Kossa stain (calcium phosphates black), magnification $160 \times$.

\section{Histological results}

Morphological examination of retrieved tissue from control and sham treated rats (Fig. 3) re- vealed diffuse mineralization in the tissue with a morphology similar to that reported in previous studies $[13,18,23]$. However, tissue implanted adjacent to refillable reservoirs had only minimal, focal calcific deposits when compared to tissue retrieved from control rats (Fig. 3). These histological findings confirm and correlate well with tissue $\mathrm{Ca}^{2+}$ determinations (Table 2). To assess potential bone-related toxicity when EHDP was administered using the Biomer ${ }^{\mathrm{TM}}$ refillable reservoirs, histological analysis was also performed on bone tissue retrieved at the time of sacrifice. Figure 4 demonstrates no significant alteration in bone morphology in EHDP-treated animals when compared with bone tissue obtained from control animals. Thus, delivery of EHDP using refillable reservoirs was not associated with disturbances to overall growth, bone development, or serum $\mathrm{Ca}^{2+}$ levels.

\section{Biomer $^{\mathrm{TM}}$ membrane surface analysis}

Figure 5 shows a scanning electron micrograph of an unimplanted (control) polyurethane reservoir membrane compared to an EHDPfilled reservoir device explanted after 21 days. Both unimplanted and explanted drug filled reservoirs demonstrated an irregular surface with a shingled appearance. Although this uniform pattern of microcracks was consistently observed, it was not associated with any fragmentation or defects in the membrane.

\section{Discussion}

The present study has successfully demonstrated that refillable polyurethane reservoirs containing EHDP may be used to inhibit CALC of glutaraldehyde-pretreated bovine pericardium when coimplanted in the accelerated rat subdermal CALC model without adverse systemic side-effects. We were unable to conclude from these findings the release rate of EHDP from the refillable reservoirs when implanted subdermally in rats adjacent to the biomaterial. Our objective was to maintain a constant (zeroorder) releasc rate of EHDP in vivo by refilling 

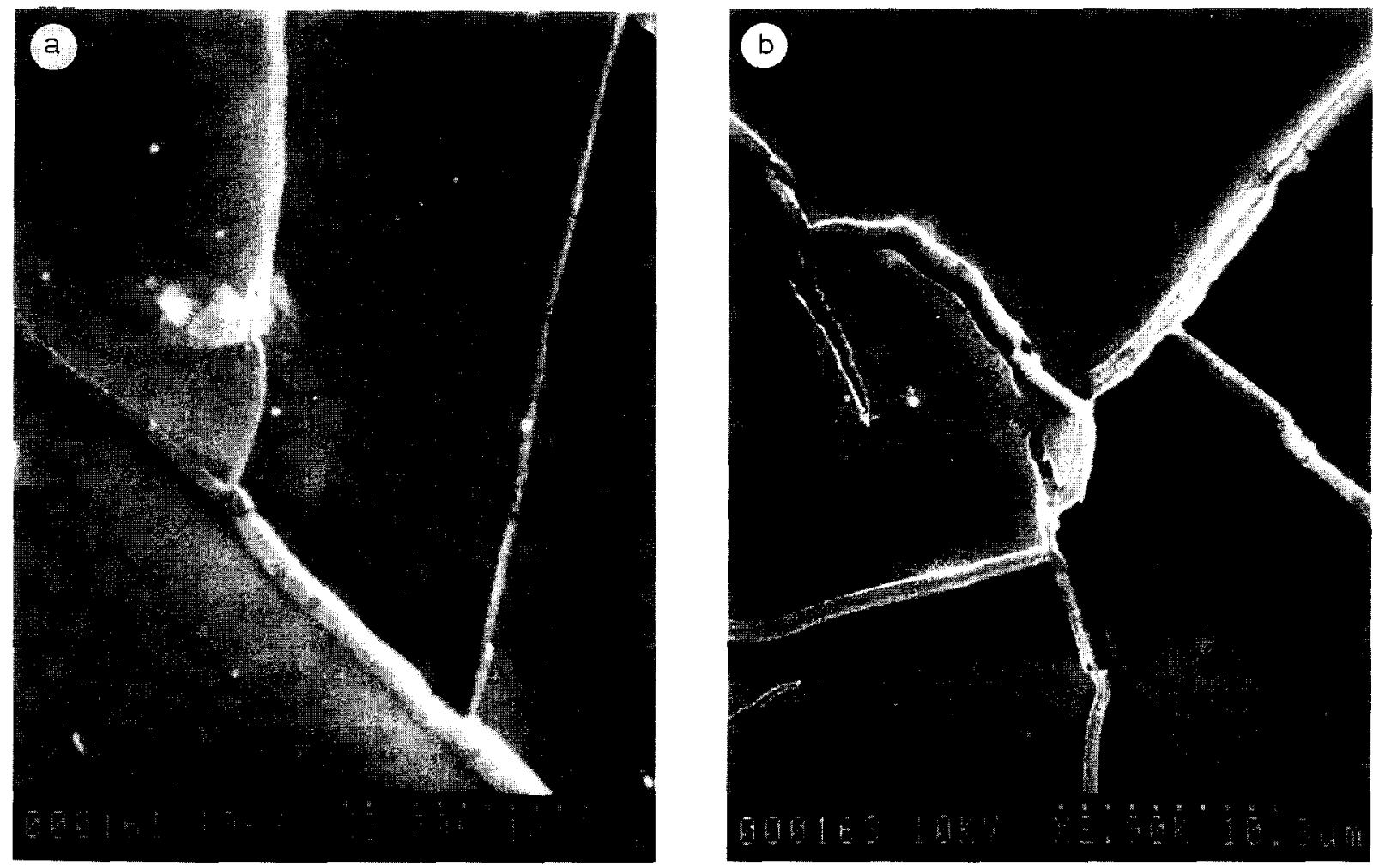

Fig. 5. Scanning electron micrographs comparing unimplanted polyurethane reservoir (a) to explanted ethanehydroxy diphosphonate (EHDP) filled reservoir, following 21 days in vivo (b). Both surfaces are remarkably similar demonstrating a somewhat shingled appearance due to uniform microcracks of the polyurethane membrane. Dotted line $=10 \mu$.

the controlled-release reservoirs at times corresponding roughly to the mean value of $t_{\text {unsat }}$ for Group 1 reservoirs evaluated for in vitro release of $\left[{ }^{14} \mathrm{C}\right]$ EHDP (Table 1). However, since the amount of EHDP that was delivered by the refillable reservoirs following the 21-day subdermal implants in rats was not assessed in the present study, two outcomes must be considered. The first outcome would be close agreement between the release rate of $\left[{ }^{14} \mathrm{C}\right] \mathrm{EHDP}$ in vitro from refillable reservoirs into a physiological buffer containing no $\mathrm{Ca}^{2+}$ (Table 1; Group 1 ) and release of EHDP in vivo, in which case, the animals would have received a dose of approximately $19.1 \pm 1.4 \mathrm{mg} / \mathrm{kg}$ per day. This dose should have resulted in adverse systemic side-effects based on previous findings [12]. Since no untoward side-effects to serum $\mathrm{Ca}^{2+}$, bone de- velopment, or overall somatic growth were noted in the present study when EHDP was delivered using the refillable reservoirs, one may conclude that the release rate of EHDP from the refillable reservoirs implanted in rats in the present study was less than the mean value of the release rate predictcd from the in vitro relcase studics employing a receptor phase containing no $\mathrm{Ca}^{2+}$ ion (Table 1; Group 1 ).

The in vivo release rate was presumably more accurately predicted by in vitro release studies utilizing a receptor phase which consisted of $\mathrm{pH}=7.4 \mathrm{HEPES}$ buffer and $1.5 \mathrm{mM} \mathrm{Ca}^{2+}$. Based on results evaluating the in vitro release of $\left[{ }^{14} \mathrm{C}\right]$ EHDP from refillable reservoirs into a physiological buffer which contained $1.5 \mathrm{mM}$ $\mathrm{Ca}^{2+}$ (Table 1, Group 2), the dose of EHDP delivered in vivo can be estimated to be approxi- 
mately $5.5 \pm 0.68 \mathrm{mg} / \mathrm{kg}$ per day. The estimated dose of $5.5 \pm 0.68 \mathrm{mg} / \mathrm{kg}$ per day should prevent CALC of glutaraldehyde-pretreated bovine pericardium implanted subdermally in rats for 21 days without untoward systemic side effects as demonstrated previously [18].

In contrast to nonrefillable polyurethane reservoirs fabricated from Mitrathane ${ }^{\mathrm{TM}}$ which were previously evaluated for efficacy at preventing CALC of glutaraldehyde-pretreated bovine pericardium [18], refillable reservoirs evaluated in the present study released EHDP at a slower rate in vivo than that predicted from our in vitro studies using a standard physiological buffer which contained no $\mathrm{Ca}^{2+}$ ion. It was demonstrated in earlier work using nonrefillable reservoirs which were solvent-cast from a $25 \% \mathrm{w} / \mathrm{v}$ Mitrathane $^{\mathrm{TM}}$ solution and which contained a 1:1 weight ratio of $\mathrm{Na}_{2} \mathrm{EHDP}$ :CaEHDP that the amount of EHDP released at 21 days following subdermal implantation in rats was approximately 5-fold greater than the amount of EHDP released from identical reservoirs evaluated in vitro [18]. This was suggested to potentially result from movement-induced flexing and bending of the nonrefillable reservoirs while in the subdermal space and possible hydrolytic degradation (biodegradation) of the polyurethane with subsequent cracking of the polyurethane membrane [24]. In addition, nonrefillable EHDP-containing reservoirs evaluated previously [18] were much larger in size (o.d. $=0.36$ $\mathrm{cm}$, i.d. $=0.33 \mathrm{~cm}$, length $=4 \mathrm{~cm}$ ) than refillable reservoirs evaluated in the present study. An increase in the amount of EHDP released from refillable reservoirs due to animal movement would appear unlikely in the present study since no disturbances to overall growth, bone formation, or serum $\mathrm{Ca}^{2+}$ levels were noted, unless the enhanced release of EHDP in vivo from Biomer ${ }^{\mathrm{TM}}$ reservoirs did not exceed a total daily dose of 15 $\mathrm{mg} / \mathrm{kg}$. Thus, the second outcome appears more likely; namely, that a reduction in the release rate of EHDP from the refillable reservoirs occurred when the reservoirs were coimplanted subdermally with glutaraldehyde-pretreated bovine pericardium in rats for 21 days compared to the release rate predicted from in vitro release studies employing a buffer devoid of $\mathrm{Ca}^{2+}$.

A decrease in the rate and extent of EHDP release from refillable reservoirs implanted adjacent to glutaraldehyde-pretreated pericardium in rats compared to the rate and amount of EHDP release predicted from in vitro release studies in which a non-calcium containing receptor phase was utilized may have occurred for several reasons. It is well documented [25-26] that lipid absorption may cause a decrease in the release rate of drugs as a function of time when controlled release devices are implanted in body tissues. This is especially true for polyurethanes such as Biomer ${ }^{\mathrm{TM}}$ [27]. In addition, since refillable polyurethane reservoirs used in this study which were implanted subdermally in rats would have been continuously bathed by interstitial fluids containing a physiological concentration of $\mathrm{Ca}^{2+}$, the potential exists for precipitation of the highly water-insoluble calcium salt of EHDP on the external surface of the rate-limiting polyurethane membrane. Precipitation of CaEHDP on the external surface of the polyurethane membrane following diffusion of EHDP through the polymer membrane might potentially restrict/ hinder release of additional EHDP from the reservoir lumen. Lastly, it is important to note that transport of the $\left[{ }^{14} \mathrm{C}\right] \mathrm{EHDP}$ anion through the polyurethane membrane represents a combination of diffusion and equilibrium between $\mathrm{Ca}^{2+}$ and EHDP. Further characterization of electrolyte diffusion through this polyurethane membrane will be the focus of future studies.

\section{Implications for drug delivery}

The refillable polyurethane reservoir devices evaluated in the present investigation have potential applications for disease states in which maximum therapeutic efficacy is achieved with prolonged, elevated concentrations of a drug substance at a specific tissue site. The commercial polyurethane investigated in our study has been suggested to be suitable for use in short-term delivery (less than 2 weeks) of uncharged waterinsoluble drugs [27]. However, we have demonstrated that refillable reservoir devices fabri- 
cated using Biomer ${ }^{\text {TM }}$ membrane may have potential bencfit in the controlled delivery of EHDP (a water-soluble, charged species) for greater than two weeks. This would allow use of the refillable reservoir devices as a site-specific delivery system which could be used in combination with EHDP-containing polymer matrices (monolithic drug delivery system), osmotic pumps, etc.

The advantage to the refillable polyurethane reservoirs evaluated in the present study was the capacity to be refilled when all or a fraction of the drug supply had been exhausted. Knowing the time required for the initially saturated $\mathrm{Na}_{2} \mathrm{EHDP}$ solution contained in the reservoir lumen to reach a drug concentration of nonconstant thermodynamic activity, it is possible for the reservoirs to be refilled at a frequency that would allow a constant (zero-order) rate of EHDP release. However, as would be expected, refilling the reservoirs at predetermined times to insure a constant rate of EHDP release in vivo assumes that release of drug in the subcutaneous environment of the rat can be accurately predicted from in vitro release studies. In addition to the advantage of a constant rate of EHDP release, the refillable reservoirs evaluated in our studies were refilled using a standard needle-injection technique; that is, reservoirs were refilled with a saturated solution of EHDP using a noninvasive technique. Replenishment of the drug supply using a polymer matrix (monolith) in which EHDP has been homogeneously dispersed is not possible post-implantation. Thus, the utility of the refillable reservoir system evaluated in the present study to the prevention of BHVCALC stems from its potential for use in combination with other successful treatment strategies aimed at inhibiting CALC of glutaraldehyde-pretreated biomaterial. Other drug delivery systems that have been successfully used to prevent CALC of glutaraldehyde-pretreated biomaterial in experimental animal models have included EHDP containing polymer matrices [6,10-11,13-16], osmotic pumps [10], and tissue pretreatment strategies $[23,28-30]$. The combination of the biocompatible refillable res- ervoir with various tissue pretreatments and EHDP-containing polymer matrices would make possible a continuous supply of EHDP to bioprosthetic tissue and avoid potential reoperation.

In conclusion, we have demonstrated that CALC of glutaraldehyde-preserved bovine pericardium implanted subdermally in rats for 21 days may be inhibited using a refillable, polyurethane reservoir drug delivery system containing EHDP when implanted adjacent to the biomaterial. The benefits of using such a system to prevent CALC of glutaraldehyde-preserved biomaterial results from its capacity to be refilled at regular time intervals by a noninvasive technique. A refillable reservoir system for the site-specific delivery of EHDP in combination with other drug delivery and tissue pretreatment strategies may potentially hold promise for the prevention of CALC of tissue contained in BHVs.

\section{Acknowledgements}

This work was supported in part by a GrantIn-Aid from the American Heart Association, National Division (T.P. Johnston) and in part by NIH Grant HL-38118 (R.J. Levy). The authors are grateful to Helen Shing and Sara Murray, Brigham and Women's Hospital, Boston, MA, for assisting in the preparation of the tissue specimens for morphological analyses. We also thank Mr Tom Underwood, University of Michigan Medical School, Ann Arbor, MI for his expert assistance with the scanning electron microscopy studies. In addition, the authors would like to acknowledge Norwich Eaton for generously supplying $\mathrm{Na}_{2} \mathrm{EHDP}$ and Dr. James $\mathrm{J}$. Benedict, formerly of Proctor and Gamble, Inc., for providing $\mathrm{Na}_{2}\left[{ }^{14} \mathrm{C}\right] \mathrm{EHDP}$. The authors are also grateful to Andy Levine and Warren Clay, formerly of Thermedics Inc., Woburn, MA, for fabrication of the reservoir devices evaluated in this study which was supported by a grant from the NHLBI (HL-38118). Lastly, the authors would like to acknowledge the expert technical assistance of Lisa D. Barkasi in the assay of tissue and serum $\mathrm{Ca}^{2+}$ concentrations. 


\section{References}

1 F.J. Schoen, H. Harasaki, K.M. Kim, H.C. Anderson and R.J. Levy, Biomaterial-associated calcification: pathology, mechanisms, and strategies for prevention, J. Biomed. Mater. Res. Applied Biomaterials, 22 (1988) 11-36.

2 G.R. Barnhart, M. Jones, T. Ishihara, A.M. Chavez, D.M. Rose and V.J. Ferrans, Failure of porcine aortic and bovinc pericardial prosthetic valves: an experimental investigation in young sheep, Circulation, 66, Suppl. I (1982) 150-153.

3 R.J. Levy, J.A. Zenker and W.F. Bernhard, Porcine bioprosthetic valve calcification in bovine left ventricle aorta shunts: studies of the deposition of vitamin K-dependent proteins, Ann. Thorac. Surg., 36 ( 1983) $187-$ 192.

4 M.J. Thurbrikar, J.D. Deck, J. Aouad and S.P. Nolan, Role of mechanical stress in calcification of aortic bioprosthetic valves, J. Thorac. Cardiovasc. Surg., 86 (1983) 115-125.

5 I. Gallo, F. Nistal, E. Artinano, D. Fernandez, R. Cayon, M. Carrion and V. Garcia-Martinez, The behavior of pericardial versus porcine valve xenografts in the growing sheep model, J. Thorac. Cardiovasc. Surg., 93 (1987) 281-290.

6 T.P. Johnston, E.L. Bove, S.F. Bolling, J.A. Boyd, B.L. Ciesliga, G.L. Amidon, F.J. Schoen and R.J. Levy, Controlled release of 1-hydroxyethylidene diphosphonate: in vitro assessment and effects on bioprosthetic calcification in sheep tricuspid valve replacements, Int. J. Pharm., 52 (1989) 139-148.

7 R.J. Levy, F.J. Schoen and S.L. Howard, Mechanism of calcification of porcine bioprosthetic aortic valve cusps: role of T-lymphocytes, Am. J. Cardiol., 52 (1983) 629631.

8 R.J. Levy, F.J. Schoen, J.T. Levy, A.C. Nelson, S.L. Howard and L.J. Oshry, Biologic determinants of dystrophic calcification and osteocalcin deposition in glutaraldehyde-preserved porcine aortic valve leaflets implanted subcutaneously in rats, Am. J. Pathol., 113 (1983) 143-155.

9 M.C. Fishbein, R.J. Levy, V.J. Ferrans, L.C. Dearden, A. Nashef, A.P. Goodman and A. Carpentier, Calcification of cardiac valve prostheses: biochemical, histologic and ultrastructural observations in a subcutaneous implantation model system, J. Thorac. Cardiovasc. Surg., 83 (1982) 602-609.

10 R.J. Levy, M.A. Hawley, F.J. Schoen, S.A. Lund and P.Y. Liu, Inhibition by diphosphonate compounds of calcification of porcine bioprosthetic heart valve cusps implanted subcutaneously in rats, Circulation, 71 (1985) 349-356.

11 R.J. Levy, J. Wolfrum, F.J. Schoen, M.A. Hawley, S.A. Lund and R. Langer, Inhibition of calcification of bioprosthetic heart valves by local controlled-release diphosphonate, Science, 228 (1985) 190-192.
12 R.J. Levy, F.J. Schoen, S.A. Lund and M.S. Smith, Prevention of leaflet calcification of bioprosthetic heart valves with diphosphonate injection therapy: experimental studies of optimal dosages and therapeutic durations, J. Thorac. Cardiovasc. Surg., 94 (1987) 551557.

13 G. Golomb, R. Langer, F.J. Schoen, M.S. Smith, Y.M. Choi and R.J. Levy, Controlled release of diphosphonate to inhibit bioprosthetic heart valve calcification: dose-response and mechanistic studies, J. Controlled Release, 4 (1986) 181-194.

14 G. Golomb, M. Dixon, M.S. Smith, F.J. Schoen and R.J. Levy, Inhibition of bioprosthetic heart valve calcification by sustained local delivery of $\mathrm{Ca}^{2+}$ and $\mathrm{Na}^{+}$diphosphonate via controlled release matrices, Trans. Am. Soc. Artif. Intern. Organs, 32 (1986) 587-590.

15 G. Golomb, M. Dixon, M.S. Smith, F.J. Schoen and R.J. Levy, Controlled-release drug delivery of diphosphonates to inhibit bioprosthetic heart valve calcification; release rate modulation with silicone matrices via drug solubility and membrane coating, J. Pharm. Sci., 76 (1987) $271-276$.

16 T.P. Johnston, E.L. Bove, S.F. Bolling, F.J. Schoen, J.A. Boyd, G. Golomb and R.J. Levy, Local controlled release of 1-hydroxyethylidene diphosphonate using silicone rubber matrices, Trans. Am. Soc. Artif. Intern. Organs, 34 (1988) 835-838.

17 G. Golomb and D. Wagner, Characterization and anticalcification effects of implantable polyurethane matrices containing amorphous dispersion of biphosphonic acid, Clin. Mater., 8 ( 1991 ) 33-42.

18 T.P. Johnston, J.A. Boyd, B.L. Ciesliga, F.J. Schoen, G.L. Amidon and R.J. Levy, Controlled release of ethanehydroxy diphosphonate from polyurethane reservoirs to inhibit calcification of bovine pericardium used in bioprosthetic heart valves, Int. J. Pharm., 59 (1990) 95104.

19 M.J. Karnovsky, A formaldehyde-glutaraldehyde fixative of high osmolality for use in electron microscopy, $\mathrm{J}$. Cell. Biol., 27 (1965) 137A.

20 Y.V. Pathak, J.A. Boyd, T.P. Johnston, J.T. Levy, G. Golomb, F.J. Schoen and R.J. Levy, Scanning electron microscopy studies of the prevention of bioprosthetic heart valve calcification with controlled release polymeric matrices, Cells Materials, 1 (1991) 65-72.

21 T.P. Johnston, C.L. Webb, F.J. Schoen and R.J. Levy, Assessment of the in vitro transport parameters for ethanehydroxy diphosphonate through a polyurethane membrane: a potential refillable reservoir drug delivery device, ASAIO J., 38 (1992) 611-616.

22 E.L. Cussler, Diffusion in concentrated solutions, In Diffusion: Mass Transfer In Fluid Systems, E.L. Cussler, Ed., Cambridge University Press, New York (1984) 55-84.

23 T.P. Johnston, F.J. Schoen and R.J. Levy, Prevention of calcification of bioprosthetic heart valve leaflets by calcium diphosphonate pretreatment, J. Pharm. Sci., 77 (1988) 740-744. 
24 R. Smith, D.F. Williams and C. Oliver, The biodegradation of poly (ether urethanes), J. Biomed. Mater. Res. 21 (1987) 1149-1166.

25 G. Benagiano, M. Ermini, C.C. Chang and K. Sundaram. Sustained release hormonal preparations, Acta Endocrinol., 63 (1970) 29-38.

26 A.S. Lifchez and A. Scommegna, Diffusion of progestogens through silastic rubber implants, Fertil. Steril., 21 (1970) 426-430.

27 G.M. Zentner, J.R. Cardinal and S.W. Kim, Progestin permeation through polymer membranes. I. Diffusion studies on plasma-soaked membranes, J. Pharm. Sci., 67 (1978) 1347-1351.

28 C.L. Webb. W.E. Flowers, J.A. Boyd, E. Rosenthal, F.J.
Schoen and R.J. Levy, $\mathrm{Al}^{3+}$ binding studies and metallic cation effects on bioprosthetic heart valve calcification in the rat subdermal model, ASAIO Trans., 36 (1990) 56-59.

29 C.L. Wcbb, J.J. Benedict, F.J. Schoen, J.A. Linden and R.J. Levy, Inhibition of bioprosthetic heart valve calcification with aminodiphosphonate covalently bound to residual aldehyde groups, Ann. Thorac. Surg., 10 (1987) 592-595.

30 C.L. Webb, F.J. Schoen, W.E. Flowers, A.C. Alfrey, C. Horton and R.J. Levy, Inhibition of mineralization of glutaraldehyde-pretreated bovine pericardium by $\mathrm{AlCl}_{3}$. $\mathrm{LaCl}_{3}$ and $\mathrm{Ca}\left(\mathrm{NO}_{3}\right)_{3}$ in rat subdermal model studies, Am. J. Pathol., 138 (1991) 971-981. 